and ionic composition. No doubt there are gels and gels; but techniques are not available to make subtle distinctions. The usual test of how an extract falls out of an inverted tube is no more scientific than the criterion advanced oy Fats Waller: that it must be jelly 'cause jam don't shake like that!

To be fair, the investigators are aware of these problems and make every attempt to relate the phenomena they are studying to cellular physiology. Already there are encouraging signs, such as that the contractile properties of a macrophage extract depend on the phagocytic activity of the cells (Stossel \& Hartwig, J. Cell Biol. 68, 602; 1976), and that cytochalasin $\mathbf{B}$ has a pronounced effect on the properties of some gel systems (Weihing J. Cell Biol. 71, 303; 1976; Hartwig \& Stossel J. Cell Biol. 71, 295; 1976). One can hope that the motile gels will be further dissected and even that they can reconcile the presently diverse views of cellular locomotion. We are so spoiled by the example of striated muscle-where the whole range of movement, from macroscopic changes in length down to molecular or even submolecular changes, can be linked in an unbroken series of logical steps that nothing less will do.

\section{Relevance of parasitology}

\author{
from F. E. G. Cox
}

The British Society for Parasitology autumn meeting on The Relevance of Parasitology to Human Welfare Today was held in London on 28 October, 1977.

THERE is no doubt that parasitology has taken off, but it is germane to ask if some of it may actually have gone into orbit. It is, therefore, essential for parasitologists to get their feet back onto the ground and that is what this meeting was about. In the morning B. O. L. Duke (World Health Organisation (WHO), Geneva) spoke about medical aspects of parasitolngy, R. B. Grifiths (Food and Agriculture Organisation, Rome) about veterinary aspects and P. T. Haskell (Centre for Overseas Pest Research, London) about agricultural aspects. In the afternoon two invited speakers commented on each of these aspects and introduced specific and general discussion.

The morning's speakers set the stage,

F. E. G. Cox is Professor of Zoology at King's College, London. summarising the main areas of interest to and reiterating the parasitological problems of the developing world. The WHO Special Programme (News and Views 262, 85; 1976) was outlined, but there can be few parasitologists who do not know what the questions are and no real attempt was made to provide any answers. The Special Programme is arguably one of the most important events in the history of parasitology and it would be a pity if it deflected attention from parasites which are not of medical importance. Griffiths left no doubt that diseases such as fascioliasis, trypanosomiasis and theileriasis maintain a stranglehold on meat production in the tropics, and singled out ticks as the major vectors of the diseases of domesticated animals. Considerable progress has been made in the control of these diseases-new and effective anti-trematode and cestode drugs such as Praziquantel are now available and successful immunisation of cattle against east coast fever has been achieved. Less dramatically it has been shown that larval stages of tapeworms which are not infective to man can be differentiated from those that are, making it possible to save vast numbers of carcasses. It may be that the amount of meat saved as a result of parasitological research is not much by western standards, but it is a major contribution towards raising the standard of living in the developing world and supporting the increasing population which will result from WHO activities.

Agricultural improvements are also necessary for the future of the developing world and there is evidence that the problems are not insoluble although insecticides will remain the major tool for many years to come. There is, however, much more that needs to be known about tropical ecosystems before it becomes possible to modify local or devise new agricultural methods, for it is now clear that the transplantation of western ideas and techniques creates new problems as well as solving some of the existing ones. In particular, the importance of plant nematodes is only just being understood (J. Bridge, Imperial College, London), and the differences between their activities in tropical and temperate lands may be immense. Land use in the tropics, especially Africa, is a perennial topic for discussion and W. E. Ormerod (London School of Hygiene and Tropical Medicine) drew attention to the limitations that soil and rain place on land use (see also Ormerod Science 191, $815 ;$ 1976). The use of indigenous animals as sources of food was discussed, but possible parasitological problems were not considered.

One of the major sources of disquiet discussed was the lack of any real future for drugs against parasitic diseases. J. F. Ryley (ICI L.td, Alderly Park) pointed out that the development of any drug was now prohibitively expensive, mainly because of the regulations embracing such developments. The WHO also laid down conditions which effectively prevented many pharmaceutical firms from cooperating in joint ventures. Participants at the meeting were pleased to learn that these conditions are to be changed.

Another source of disquiet was the lack of career prospects for young parasitologists. Graduate unemployment is a world-wide problem and developing countries naturally wish to employ nationals in WHO and other schemes. The disenchantment of young people who have a real interest in parasitology and its direct application but who find that they cannot work where they feel they are needed is real. G. S. Nelson (London School of Hygiene and Tropical Medicine) drew attention to the achievements of parasitologists in the past and the important discoveries made by Britons in this field. It may well be that, in the past, devoted parasitologists working in less than optimal conditions took the assistance of local staff for granted. Perhaps the great discoveries yet to come will be made by local parasitologists and young Americans and Europeans will be better employed as their highly skilled technicians. It takes courage and real devotion to do the work and receive none of the glory, but the great achievements listed by Nelson were those of men who thought more about sick Africans than the number of papers published.

\section{Two-photon ionisation interference effects}

from Peter Knight

AN atom in a moderately intense laser field can ionise by absorbing more than one photon, and multiphoton ionisation is a very active subject at the moment. For example, it was hoped that the multiphoton ionisation of an alkali could provide, by courtesy of the spin-orbit interaction, a useful source of spinpolarised electrons. Preliminary experiments were performed at several laser wavelengths on the two-photon nonresonant ionisation of atomic caesium (Cs: $2 h \omega-\mathrm{Cs}^{+}+\mathrm{e}$ ) by Van der Wiel and

Peter Knight is Jubilee Research Fellow in the Department of Physics at Royal Holloway College, London. 